\title{
KNOWLEDGE \& PRACTICE OF NURSING ETHICS AND LAWS
}

\author{
Shrestha $\mathrm{S}^{1}$, Jose $\mathrm{P}^{2}$
}

\section{ABSTRACT}

INTRODUCTION: Nurses are responsible for the well-being and quality of life of many people, and therefore must meet high standards of technical and ethical competence. Values are the belief and attitude that influence individual behavior and process of decision making. Personal values are what nurses hold significant and true for themselves, while professional ethics involve principles that have universal applications and standards of conduct that must be upheld in all situations. From the previous study it was found that most of the nurses have the knowledge regarding nursing ethic and law but have lack of practice.

METERIAL AND METHODS: A descriptive cross sectional study was conducted among the selected nurses of Universal College of Medical Sciences and Teaching Hospital (UCMS TH) Bhairahawa Nepal. Population for the study was selected on random basis and total sample size was 60 . A self-administered structured questionnaire about knowledge of nursing ethics and law was devised, tested and distributed to the nurses and practice of same sample was assessed through checklist by observing the activities of nurses by the researcher herself.

RESULTS: Among the total 60 respondents only $45 \%$ had adequate knowledge of ethics and rest of them had inadequate knowledge regarding nursing ethics whereas most of the respondents i.e. 53\% had adequate knowledge of nursing law and only $46 \%$ had inadequate knowledge of it. On the other hand half of the respondents do practice on nursing ethics and law and another half do less practice. As a whole it has been identified that respondents had more knowledge of nursing law than that of nursing ethics and half of them do practice on it.

CONCLUSION: Findings of the study showed that knowledge of law was greater than knowledge of ethics. Overall they had no satisfactory knowledge of ethics and law. Whereas $50 \%$ of respondents does adequate practice.

KEYWORD: Ethics, Law, Nursing ethics

1. Nursing Tutor,Universal College of Nursing Sciences, Bhairahawa, Nepal

2. Assistant Professor, Universal College of Nursing Sciences, Bhairahawa, Nepal

\author{
For correspondence \\ Pradap Jose (M.Sc Nursing) \\ Assistant Professor, \\ Universal College of Nursing Sciences, Bhairahawa, Nepal \\ E-mail: pradappauljose@gmail.com
}




\section{INTRODUCTION}

Different patient have different value and belief and nurses have to think about their value and belief while providing nursing care to them. If not so then dilemmas may occur when different value conflict. ${ }^{1,2}$ For example client's right to refuse treatment may be in conflict and carry out treatment. Nurse can make better moral decision by thinking in advance about their beliefs and moral value and about the kinds of problem they may encounter while caring for the patient. Every nurse patient contact can produce a legal or ethical situation. ${ }^{3}$

Ethics deals with standards of conduct and moral judgment. The major principles of healthcare ethics that must be upheld in all situations are beneficence, non- malfeasance, autonomy, and justice. Beneficence means promoting or doing good. Nurses work to promote their clients' best interests and strive to achieve optimal outcomes. Non malfeasance means avoiding harm. Nurses must maintain a competent practice level to avoid causing injury or suffering to clients. The principle of non- malfeasance also covers reporting suspected abuse to prevent further victimization and protecting clients from chemically impaired nurses and other healthcare practitioners. Autonomy stands for independence and the ability to be self-directed. Clients have the right of selfdetermination and are entitled to decide what happens to them; therefore, competent adults have the capacity to consent to or refuse treatment. Nurses must respect the client's wishes, even if they don't agree with them. Finally, justice requires that all clients be treated equally and fairly. Nurses face issues of justice daily when organizing care for their clients and deciding how much time they will spend with each based on client needs and a fair distribution of resources.

Since nurses address complex ethical and human rights issues on a regular basis, the American Nurses Association Board of Directors and the Congress on Nursing Practice first initiated the code of ethics for nurses in 1985 to delineate the code of responsibilities and conduct expected of nurses in their practice. Nurses are held responsible to comply with the standards of ethical practice and to ensure that other nurses also comply. The code was revised in 2001 to include issues of advancing nursing science and is based on the opinions and experience of a wide range of nurses. The ANA approved nine provisions that address ethical practice issues such as compassion and respect, the nurse's primary commitment to the patient, patient advocacy, responsibility and accountability, duties, participation in the healthcare environment, advancement of the profession, and collaboration. $^{4}$

On the other hand law is a system composed of general rules, governing conduct and the procedures for solving disputes when rule are not followed. When laws are broken, it is punishable by an authority figure. Laws are those rules made by humans which regulate social conduct in a formally prescribed and legally binding manner.

Legal responsibilities are defined as those which a nurse must obey as a law in a professional manner. Legal aspect is defined an $s$ the activity of the nurse that legally permitted while taking care of the sick patient. Law is final authority to regulate the activities of all citizens. Nurse need to be aware of this standard, as well as legal and ethical concept and principles since nurse are accountable for their action in these areas in their professional role. Legal aspect may differ from country to country depending on their law and code of ethics. ${ }^{5}$

A study conducted in USA regarding the difficult patient reconceived : an expanded moral mandate showed that between 15 and $60 \%$ of patient treated by physician are considered difficulties. Psychiatric pathology of patient is an conventional explanation that the patient are in difficulties . The possibility of less pathological cause is suggested by prevalence of the problem. There is an ethical force to address the perception of harm if there are ground to reconceived the 'difficult' patient are reacting to the perception of ill treatment. But ethical stakes make this conflict into the province of the ethical consult service. As the resource for addressing ethical dilemmas, there is a moral mandate to offer assistance in the resolution of these ethically charged conflicts that is no less pressing than the more familiar terrain of clinical ethics consultation. ${ }^{6}$ As the different research regarding ethics and law had been conducted in different country and now by conducting this research over here we can get an idea what is the level of knowledge and what are the practices of it in UCMS TH.The main objective of this study was to assess the knowledge and practice of nursing ethics and law among nurses.

\section{MATERIAL AND METHODS}

The descriptive cross sectional study was conducted in 
UCMS TH from $30^{\text {th }}$ March to $27^{\text {th }}$ April 2013. Institutional approval was taken. All the interested registered, staff nurses and axillaries nurse midwifery, were included and all the community medical assistant, voluntary nurses, nursing student and the nurses who are not being registered in nursing council were excluded from the study. The total sample size was sixty which was taken on random basis. A structured questionnaire was used to assess the knowledge of nursing ethic and law and practice was assessed through the checklist. The number of items prepared was 22, 11 related to ethics and 11 related to law which was filled by the respondent in 30 minutes. Similarly checklist consisted 15 questions which were checked by the researcher herself. Validity was maintained by sending the questionnaire to experts and reliability was assessed by conducting pre-test on 10 samples in Butwal Hospital Private Limited, Butwal.The data was analyzed by using appropriate descriptive statistics (Mean, standard deviation). All collected data were arranged in order. Coding of the questionnaire was done before entering into the SPSS for window programmer. All completed data were arranged, checked, classified, coded and tabulated to make it clear and scientific. Data were entered in Microsoft excel 2007 and analyzed in SPSS version 16. The data were analyzed using frequency, distribution and percentage by using tables. The data were scored and labeled as adequate knowledge and inadequate knowledge as well as adequate practice and inadequate practice on ethics and law. Association between knowledge and practice of ethic and law was also assessed.

\section{RESULT}

According to the analysis from the total 60 respondents only $45 \%$ respondents had adequate knowledge and rest of them had inadequate knowledge regarding ethics. On the other hand from the total 60 respondents $53 \%$ of respondents had adequate knowledge of law and other $46.7 \%$ of respondents had inadequate knowledge of law. Whereas $50 \%$ of respondents had adequate practice and other $50 \%$ of respondents had inadequate practice of ethics and law. Study showed that the value of ethics and law was more than 0.05 so there was no any association between knowledge and practice of nursing ethics and law and also no any association between demographic variable and law, but there was association between marital status and knowledge of ethics.
Table 1. Socio demographic characteristics

\begin{tabular}{|c|c|c|}
\hline Characteristics & Frequency & Percentage \\
\hline \multicolumn{3}{|l|}{ Age } \\
\hline 18 to 26 & 48 & 80 \\
\hline 27 to 35 & 10 & 16.7 \\
\hline 36 to 44 & 1 & 1.7 \\
\hline$>45$ & 1 & 1.7 \\
\hline \multicolumn{3}{|l|}{ Marital status } \\
\hline Married & 19 & 31 \\
\hline Unmarried & 40 & 66.7 \\
\hline Widow & 1 & 1.7 \\
\hline \multicolumn{3}{|l|}{ Clinical experience } \\
\hline 0 to 9 & 50 & 83.3 \\
\hline 10 to19 & 6 & 10 \\
\hline 20 to 29 & 3 & 5 \\
\hline 30 year and above & 1 & 1.7 \\
\hline \multicolumn{3}{|l|}{ Education status } \\
\hline ANM & 11 & 18.3 \\
\hline BSc/BN NURSING & 7 & 11.7 \\
\hline PCL & 42 & 70 \\
\hline \multicolumn{3}{|l|}{ Area of practice } \\
\hline medical/surgical & 13 & 21.7 \\
\hline Emergency & 5 & 8.3 \\
\hline Pediatric & 3 & 5 \\
\hline Psychiatric & 1 & 1.7 \\
\hline ICU/CCU & 8 & 13.3 \\
\hline GYE AND OBS & 7 & 11.7 \\
\hline Other & 23 & 38.3 \\
\hline \multicolumn{3}{|l|}{ Designation } \\
\hline ward staff & 51 & 85 \\
\hline ward in charge & 9 & 15 \\
\hline
\end{tabular}

Table 1 shows the socio demographic characteristics of the respondents. Most of the respondents were 18 to 26 ages i.e. of $(80 \%)$. Among them $66.7 \%$ were unmarried. More than 50\% of respondent had 0 to 9 year clinical experience and few of them i.e. $1.7 \%$ only had 30 years and above clinical experiences. Majority of the respondents who involved in research were more from other area (neurology, major and 
minor OT) and very few were from psychiatric and pediatrics. $21.7 \%$ of respondents were from Medical/Surgical and 13.3 were from ICU/CCU. Similarly $85 \%$ of respondents were ward staff and $15 \%$ were ward in charge.

\section{Figure1: Overall knowledge of ethics}

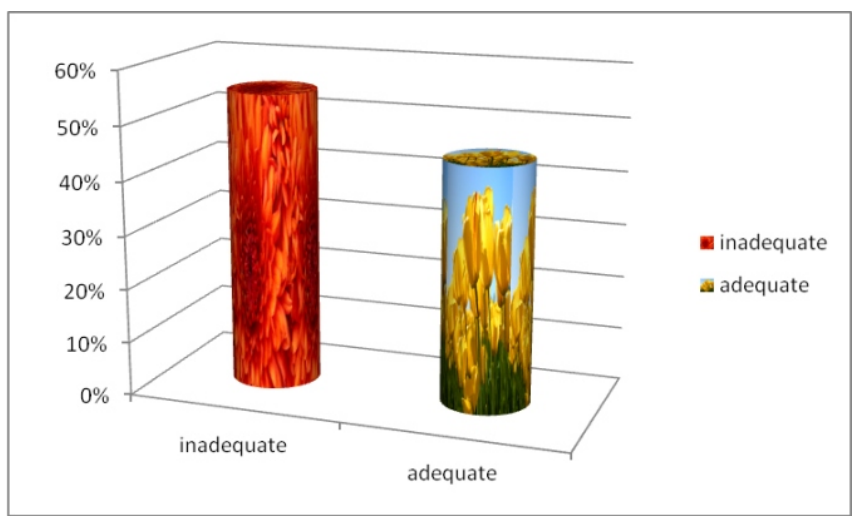

Figure 2: Overall knowledge score of law

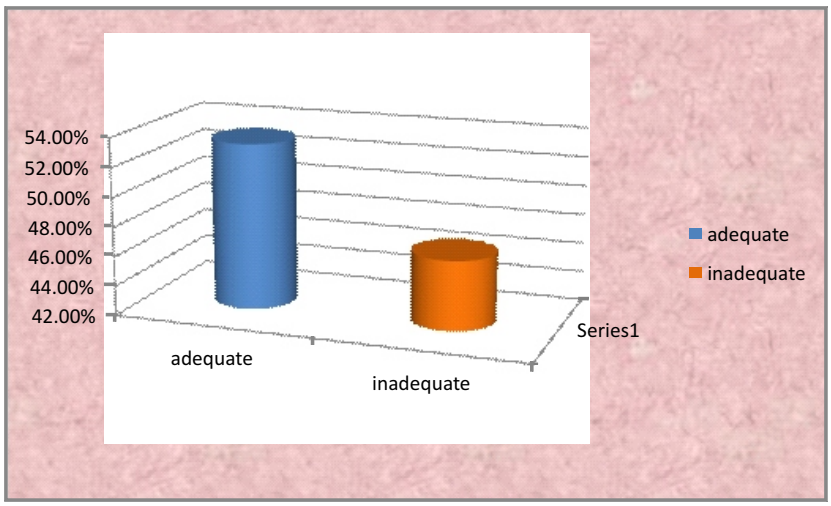

Figure 3: Overall practice of ethics and law

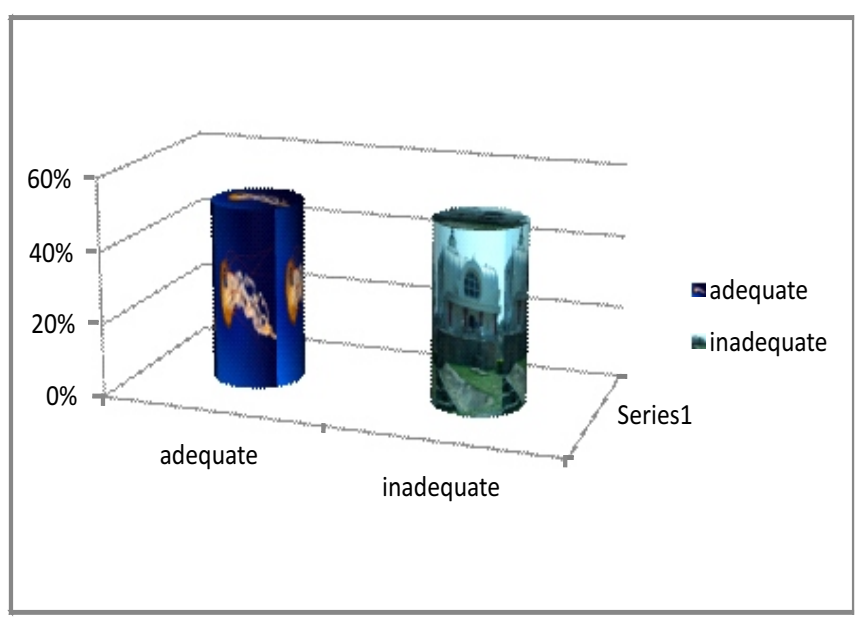

\section{DISCUSSION}

A study conducted in medical students at Barbados generally understand the importance of ethical knowledge and the majority answered correctly to questions designed to test how they would respond in situations which deal with the nuances of consent, confidentiality and patient autonomy. There were substantial minorities of students who were uncertain or incorrect on the questions pertaining to dealing with relatives, religious conflict situations and violent patients. The students responded that they knew little of the law, and were unaware of codes of conduct other that the Hippocratic Oath. ${ }^{7}$ Whereas present study shows that most of the respondents have more knowledge on law than ethics, whereas half of the respondents do practice of ethics and law but rest half donot follow ethic and law.

\section{CONCLUSION}

According to the data total mean knowledge of ethics was 7.2500; law was 7.3333 and similarly means practice of respondents was 10.28. Finding of the study showed that knowledge of law was greater than knowledge of ethics. Overall they had no satisfactory knowledge of ethics and law. Whereas $50 \%$ of respondents does adequate practice.

\section{REFERENCE}

1. Rai, L., Nursing concept theories and principles, 2011,pg 250 .

2. Nursing ethics and legal issues, www.education.com/ reference/article/nursing ethics.

3. Rai, L., Nursing concept theories and principles, 2011, pg 250.

4. Nursing ethics and legal issues, www.education.com/reference larticle/nursing ethics.

5. Rai, L., Nursing concept theories and principles, 2011, pg 255, 258

6. Fiester, A., The difficult patient reconceived an expanded moral mandate for clinical ethics, The American Journal of Bioethics.

7. Hariharan, S., et al., Knowledge, Attitude and Practice of health care ethics and law among doctors and nurse in Barbados, June 2006, BMC Medical Ethics, Volume 7. 